\title{
Viral infections and cell cycle G2/M regulation
}

\author{
Richard Y. ZHAO ${ }^{1,2, *}$, Robert T. ELDER ${ }^{2}$ \\ ${ }^{I}$ Department of Pathology and Microbiology-Immunology, Institute of Human Virology, University of Maryland School of \\ Medicine, Baltimore, MD 21201, USA \\ ${ }^{2}$ Children's Memorial Research Center, Northwestern University Feinberg School of Medicine, Chicago, IL 60614, USA
}

\begin{abstract}
Progression of cells from G2 phase of the cell cycle to mitosis is a tightly regulated cellular process that requires activation of the Cdc2 kinase, which determines onset of mitosis in all eukaryotic cells. In both human and fission yeast (Schizosaccharomyces pombe) cells, the activity of Cdc2 is regulated in part by the phosphorylation status of tyrosine 15 (Tyr15) on Cdc2, which is phosphorylated by Wee1 kinase during late G2 and is rapidly dephosphorylated by the Cdc 25 tyrosine phosphatase to trigger entry into mitosis. These Cdc2 regulators are the downstream targets of two wellcharacterized G2/M checkpoint pathways which prevent cells from entering mitosis when cellular DNA is damaged or when DNA replication is inhibited. Increasing evidence suggests that Cdc2 is also commonly targeted by viral proteins, which modulate host cell cycle machinery to benefit viral survival or replication. In this review, we describe the effect of viral protein $\mathrm{R}$ (Vpr) encoded by human immunodeficiency virus type 1 (HIV-1) on cell cycle G2/M regulation. Based on our current knowledge about this viral effect, we hypothesize that Vpr induces cell cycle G2 arrest through a mechanism that is to some extent different from the classic G2/M checkpoints. One the unique features distinguishing Vpr-induced G2 arrest from the classic checkpoints is the role of phosphatase 2A (PP2A) in Vpr-induced G2 arrest. Interestingly, PP2A is targeted by a number of other viral proteins including SV40 small T antigen, polyomavirus $\mathrm{T}$ antigen, HTLV Tax and adenovirus E4orf4. Thus an in-depth understanding of the molecular mechanisms underlying Vpr-induced G2 arrest will provide additional insights into the basic biology of cell cycle G2/M regulation and into the biological significance of this effect during host-pathogen interactions.
\end{abstract}

Keywords: HIV-1, Vpr, cell cycle G2/M regulation, DNA damage, DNA replication, checkpoints, viral infections, fission yeast, Schizosaccharomyces pombe.

\section{CELL CYCLE G2/M CONTROLS AND CHECK- POINTS}

To insure the accurate transmission of genetic information, eukaryotic cells have developed an elaborate network of checkpoints to monitor the successful completion of every cell cycle step and to respond to cellular abnormalities such as DNA damage and replication inhibition as they arise during cell proliferation. The two best characterized checkpoints are those for DNA damage and DNA replication (Fig.1A, top. For reviews, see ref [1-4]). Activation of either of these two checkpoints causes a cell cycle arrest, and they were first characterized in detail by genetic analysis in fission yeast (Schizosaccharomyces pombe). The $\mathrm{G} 2$ to $\mathrm{M}$ transition is controlled in fission

*Correspondence: Richard Y. ZHAO

E-mail: RZhao@som.umaryland.edu yeast by the phosphorylation status of Tyr15 on $\mathrm{Cdc} 2$, the cyclin-dependent kinase which regulates the cell cycle in all eukaryotic cells [5]. In fission yeast, Tyr15 is phosphorylated by the Wee1 and Mik1 kinases to hold the cell in G2, and rapid dephosphorylation by the Cdc25 phosphatase triggers the $\mathrm{G} 2$ to $\mathrm{M}$ transition [5-8].

The DNA damage checkpoint (Fig. 1A, top) is activated by ionizing radiation or ultraviolet light, and activation of this checkpoint leads to inhibitory Tyr 15 phosphorylation of Cdc 2 by a multistep pathway $[9,10]$. The early genes in the pathway, which include $\operatorname{Rad} 1, \operatorname{Rad} 3, \operatorname{Rad} 9, \operatorname{Rad} 17$, Rad26 and Hus1, are thought to sense the DNA damage and lead to phosphorylation of the Chk1 protein [11]. In response to double strand DNA breaks (DSBs) induced by ionizing radiation, for example, Rad17 acts as a checkpoint-specific loading factor, which responds to the DNA damage by loading a 9-1-1 protein complex onto the sites where DNA is damaged $[12,13]$. The $9-1-1$ protein com- 
A

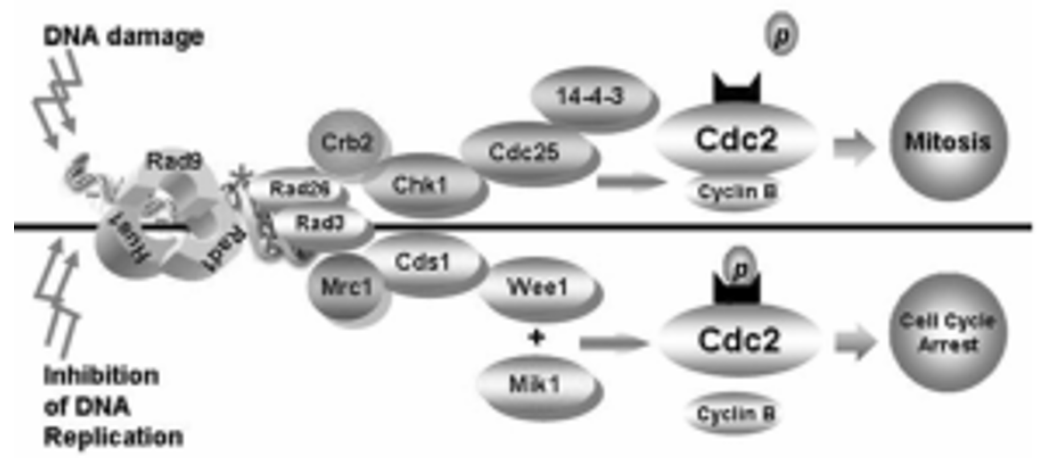

B

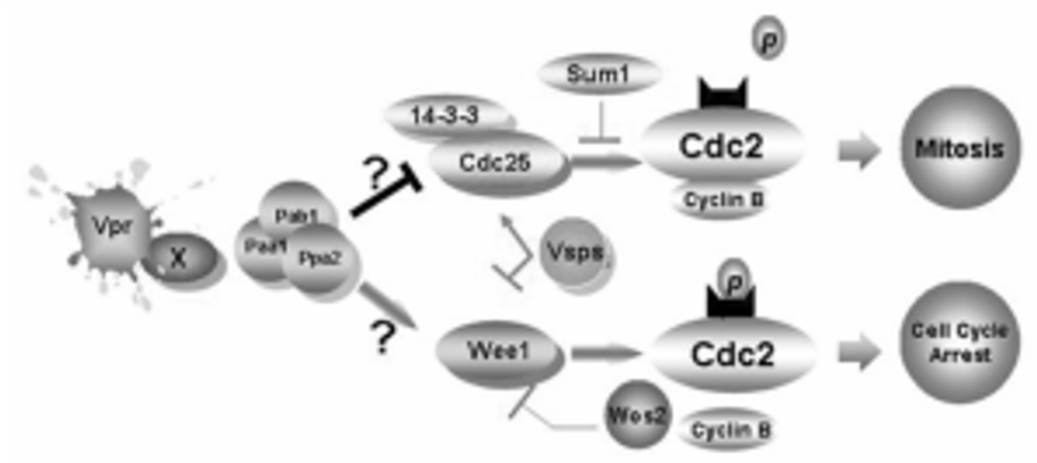

Fig. 1 Models for the classic cell cycle G2/M checkpoints and HIV-1 Vpr-induced cell cycle G2/M regulation. (A) Pathway for DNA damage and replication checkpoints in fission yeast. (B) Current model for Vpr-induced G2 arrest. The X indicates that Vpr may bind to cellular protein(s) and regulates the PP2A holozyme. $\rightarrow$, activation; - , inhibition; ?, unknown.

plex is also known as the checkpoint clamp complex (CCC), which is composed of Rad1, Rad9 and Hus1 [13]. In addition, the Rad3-Rad26 protein complex also binds to sites of DNA damage independently of the 9-1-1 protein complex. The independent binding of two protein complexes to DNA damage to initiate the DNA structure checkpoint is believed to protect the cell against inappropriate checkpoint activation $[2,13,14]$. Activation of Chk1 is mediated by Crb2, which may bridge Rad 3 and Chk1 [1517]. The activated Chk1 kinase then directly phosphorylates the Cdc25 phosphatase [18]. The phosphorylated Cdc25 binds Rad24/25 (14-3-3) protein, and this complex is transported out of the nucleus to render Cdc25 inactive [19]. The activated Chk1 also regulates the Mik1 kinase to inhibit Cdc2 [20]. DNA damage thus initiates a Chk1-mediated protein phosphorylation cascade ending in the inactivation of Cdc 25 phosphorylase and activation of Mik1 kinase to increase inhibitory phosphorylation of Tyr15 on Cdc2.

The DNA replication checkpoint (Fig. 1A, bottom) is activated by treatment with hydroxyurea, which inhibits DNA replication, and this checkpoint also controls the G2 to $\mathrm{M}$ transition through inhibitory phosphorylation of $\mathrm{Cdc} 2$ [10]. Parts of this DNA replication checkpoint are shared with the DNA damage checkpoint as $\operatorname{Rad} 1, \operatorname{Rad} 3, \operatorname{Rad} 9$, Rad17, Rad26 and Hus1 are required for both checkpoints in fission yeast [21]. The same 9-1-1 and $\operatorname{Rad} 3-\operatorname{Rad} 26$ checkpoint protein complexes may associate with the DNA replication complex [13]. However, the DNA replication checkpoint acts primarily through phosphorylation of Cds1 kinase, which is mediated by another protein Mrc1 [22, 23], with minor participation of Chk1 kinase, and either kinase is sufficient by itself to give cell cycle arrest when DNA synthesis is inhibited [24]. Activated Cds1 kinase inactivates Cdc25 through a similar mechanism as Chk1 [1, 24]. Cds1 also activates the Mik1 kinase, which phosphorylate Tyr15 of Cdc2 [25].

Cell cycle G2/M controls, which were often initially defined in fission yeast, are highly conserved, and most of the genes required for the checkpoints have human homologues (Tab. 1). In general, these homologues have similar, although not always identical, roles in the control of the human cell cycle. There is a tendency for multiple, partially redundant checkpoints in human cells compared to 
Tab. 1 Functional conservation of cell cycle G2/M machinery between human and fission yeast

\begin{tabular}{|c|c|c|}
\hline Fission Yeast & Human & Putative Activity \\
\hline \multicolumn{3}{|c|}{ Mitotic regulators } \\
\hline $\mathrm{Cdc} 2$ & CDK1 & Cyclin B-dependent kinase \\
\hline $\mathrm{Cdc} 13$ & Cyclin B & B-type cyclin \\
\hline Wee1 & WEE1 & Tyrosine kinase \\
\hline Mik1 & - & Tyrosine kinase \\
\hline $\mathrm{Cdc} 25$ & $\mathrm{CDC} 25 \mathrm{~A} / \mathrm{B} / \mathrm{C}$ & Tyrosine phosphatase \\
\hline \multicolumn{3}{|c|}{ DNA damage and replication checkpoints } \\
\hline Rad1 & hRAD1 & Nuclease \\
\hline $\operatorname{Rad} 3$ & ATM/ATR & Protein kinase \\
\hline Rad9 & hRAD9 & 3'-5' exonuclease \\
\hline $\operatorname{Rad} 17$ & hRAD17 & Unknown \\
\hline $\operatorname{Rad} 24 / 25$ & $14-3-3$ & Binds to phosphorylated ser \\
\hline $\operatorname{Rad} 26$ & ATRIP & Rad3 regulatory protein \\
\hline Hus 1 & hHUS1 & A PCNA-related protein \\
\hline Chk1 & CHK1 & Serine/Threonine Kinase \\
\hline Cds 1 & CHK2 & Serine/Threonine Kinase \\
\hline $\mathrm{Crb} 2$ & BRCA1 & Unknown \\
\hline Mrc 1 & CLSPN & Unknown \\
\hline \multicolumn{3}{|c|}{ Cellular proteins involved in Vpr-induced G2 arrest } \\
\hline PP2A & PP2A & Protein phosphatase 2A \\
\hline Paa1 & A & A regulatory subunit \\
\hline Pab1 & $\mathrm{B}$ & $B$ regulatory subunit \\
\hline Ppa2 & $\mathrm{C}$ & $\mathrm{C}$ catalytic subunit \\
\hline Ppa1 & $\mathrm{C}$ & $\mathrm{C}$ catalytic subunit \\
\hline Wos 2 & $\mathrm{P} 23$ & Inhibitor of Wee1 \\
\hline
\end{tabular}

Note: “_”, not found.

simpler checkpoints in yeast probably reflecting the more complex requirements for cell cycle control in multicellular eukaryotes. For example, the single rad 3 gene in fission yeast is required for both the DNA damage and replication checkpoints and activation of the $\operatorname{chkl}$ and $c d s 1$ checkpoint kinases $[2,13,14]$. In human cells there are two homologues of $\mathrm{rad} 3, A T M$ and $A T R$. The primary role of $A T M$ is in the DNA damage checkpoint initiated by double strand breaks and activation of $C H K 2$, the human homologue of $c d s 1$, whereas the primary role of the essential ATR gene is in the DNA replication checkpoint or responses to many forms of DNA damage and activation of CHK1 [26, 27]. Similarly, there is only one tyrosine phosphatase $\mathrm{Cdc} 25$ that dephosphorylates $\mathrm{Cdc} 2$ in fission yeast. In human cells, there are three CDC25 homologues, CDC25A, CDC25B and CDC25C, and each of them can be phosphorylated by CHK1 [28]. All three of these phosphatases have been shown to be involved in the control of the G2/M transition, even though their specific roles in this process have not yet been well characterized [29-31]. The $p 53$ gene is an example of an additional level of cell cycle control in human cells. The p 53 transcription factor, which has no homologues in yeast, has multiple roles including regulating the cell cycle and apoptosis with an essential role in the G1 DNA damage checkpoint [32]. It also has important roles in the G2 damage checkpoint. It inhibits Cdc2 through activation of Gadd45, p21, and 14-3-3 $\sigma$. In addition, it is involved in regulatory feedback loops with ATM/ATR and CHK1 [33]. The conservation of checkpoints even extends to the regulatory mechanisms as illustrated by the negative regulation of $\mathrm{CDC} 25$ by relocation to the cytoplasm from the nucleus in both fission yeast and human cells. This relocation in both organisms is dependent on 14-3-3 proteins [19, 34].

\section{CELL CYCLE G2/M ARREST INDUCED BY HIV-1 VPR}

The HIV-1 Vpr protein induces cell cycle G2 arrest 
through inhibitory phosphorylation of $\mathrm{Cdc} 2$ both in fission yeast and human cells, suggesting that Vpr affects a conserved cellular process. Specifically Vpr induces hyper-phosphorylation of fission yeast $\mathrm{Cdc} 2$ or human CDK1, the human homologue of Cdc2 [35-37]. It exerts its inhibitory effect through T14A and Y15F of CDK1 and $\mathrm{Y} 15 \mathrm{~F}$ of $\mathrm{Cdc} 2$, as expression of nonphosphorylatable Cdc2 mutants, T14A Y15F of CDK1 and Y15F of Cdc2, prevents Vpr-induced G2 arrest [36, 38]. Furthermore, Vpr inhibits Cdc25 phosphatase $[39,40]$ and activates Wee 1 kinase $[39,41]$ to promote phosphorylation of $\mathrm{Cdc} 2 /$ CDK1 during induction of G2 arrest. Consistent with the roles of Wee 1 and Cdc25 in Vpr-induced G2 arrest, proteins which regulate $\mathrm{Cdc} 25$ or Wee1 have been shown to either augment or alleviate Vpr-induced G2 arrest. For example, fission yeast Wos2, which is a homologue of human p23 and a Wee1 inhibitor [42], is a Vpr suppressor when overproduced [39]. The Cdc25 inhibitor rad25 [19], which is a homologue of human 14-3-3 proteins, enhances Vpr-induced G2 arrest when overproduced in fission yeast [39]. Recent studies further show that Vpr binds to Cdc25C and to 14-3-3 in human cells [43-45].

Given that the DNA checkpoints and Vpr both induce G2 arrest through inhibitory phosphorylation of Cdc2 which is regulated by Wee 1 and Cdc25, Vpr might induce G2 arrest through a checkpoint pathway. This possibility has been evaluated in fission yeast by expressing $v p r$ in mutant fission yeast strains defective in early and late steps of the checkpoint pathways. None of the early checkpoint-specific mutants ( $\mathrm{rad} 1, \mathrm{rad} 3, \mathrm{rad} 9$ and $\mathrm{rad} 17$ ) showed a significant effect on the induction of G2 arrest by $\operatorname{Vpr}[38,39,46]$. Furthermore, mutations in both chk1 and $c d s 1$, which are thought to be the last steps specific for the checkpoint $[1,18,24]$, also do not block Vprinduced $\mathrm{G} 2$ arrest $[39,46]$. Therefore, $\mathrm{Vpr}$ does not appear to use the DNA-damage or DNA-replication checkpoint pathways to induce G2 arrest in fission yeast.

Early data in human cells tended to support the conclusion that Vpr does not induce G2 arrest through the DNA damage checkpoint pathways. Vpr still induced G2 arrest in cells from patients with ataxia telangiectasia (AT) [40]. These AT cells are mutant for the ATM gene, which is a human homologue of fission yeast Rad3, and they do not arrest in G2 in response to DNA damage caused by ionizing radiation [47-49]. However, recent reports show that Vpr activates ATR, the second human homologue of fission yeast $\operatorname{Rad} 3$, and other steps in this checkpoint pathway such as RAD17, HUS1, BRCA1 and $\gamma$-H2AX [50, 51]. Down-regulation of ATR or CHK1 by RNAi partially attenuated Vpr-induced G2 arrest [50, 51]. These studies suggest that Vpr may induce G2 arrest through a cellular response to DNA replication stress or to a signal that "mimics" DNA damage. However, expression of vpr does not increase gene mutation frequency [52], which argues against the possibility that Vpr actually causes DNA damage. It is thus reasonable to think that other signals other than actual DNA damage triggers DNA damage-like cellular responses. These cellular responses could include the nuclear herniation caused by Vpr [53] or cellular stress responses to $v p r$ gene expression [54-56]. Since ATR and CHK1 have primary roles in the responses to changes in DNA replication, an alternative possibility is that Vpr may interfere with DNA replication. This possibility is certainly supported by a number of reports showing that $\mathrm{Vpr}$ induces genomic instability, formation of micronuclei and aneuploidy [57, 58]. All of these changes in DNA structures could be perceived as replication stresses, which would trigger cell cycle arrest.

Considering that G2/M DNA checkpoints are highly conserved between mammalian and fission yeast cells (Tab. 1), it is unclear at the moment why human ATR and CHK1 are activated by Vpr but rad3 (the fission yeast homologue of ATR/ATM) or chk1/cds 1 (CHK1/CHK2) double deletion in fission yeast does not block Vpr-induced G2 arrest [38, 39]. One factor possibly contributing to the observed activation of ATR in mammalian cells is that retroviral integration appears to activate ATR [59], and the experiments showing activation of ATR by Vpr were done with lentiviral vectors which might therefore activate ATR to some extent independently of Vpr. In addition, it was noticed that activation of ATR and CHK1 only accounts for part of the G2 arrest induced by Vpr [50]. Other as yet unidentified molecular mechanism(s) may explain at least half of the $\mathrm{G} 2$ cell population induced by Vpr. Interestingly, Roshal et al [60] showed that treatment of Vpr-producing mammalian cells with caffeine completely blocks Vpr-induced G2 arrest. Caffeine is part of the methylxanthine family, and similar to the caffeine effect, another methylxanthine pentoxifylline (PTX) also inhibits Vpr-induced G2 arrest in mammalian cells [61]. Similarly, both PTX and caffeine suppress Vpr-induced G2 arrest in fission yeast $[39,58]$ [our unpublished data]. Since PTX or caffeine inhibits Vpr-induced G2 arrest in fission yeast where the classic DNA checkpoints apparently play no role, these observations suggest molecular mechanisms other than the classic DNA checkpoints may be involved in activation of ATR and regulation of Cdc 25 and Wee1.

The additional molecular mechanism might involve protein phosphatase $2 \mathrm{~A}$ (PP2A). Although this protein phosphatase has no known role in the DNA checkpoints, it has an important role in Vpr-induced G2 arrest. Okadaic acid is a specific inhibitor of PP2A, and okadaic acid was shown to inhibit Vpr-induced G2 arrest both in human [35] and fission yeast cells [37]. Further evidence for an important 
role of PP2A comes from PP2A mutant strains. PP2A is composed of three subunits, one catalytic (C) and two regulatory (A and B) subunits. When $v p r$ was expressed in a strain with a deletion for a catalytic subunit (ppa2) or a regulatory subunit (pab1) of PP2A, Vpr-induced G2 arrest was reduced $[39,46]$. Taken together, it is possible that a concerted cellular mechanism interlinks PP2A and possibly ATR/CHK1 in the cellular response to $v p r$ gene expression during the induction of G2 arrest.

\section{POTENTIAL ROLE OF PP2A IN CELL CYCLE G2/M REGULATION DURING VIRAL INFEC- TIONS}

Other evidence supporting involvement of PP2A in Vprinduced $\mathrm{G} 2$ arrest comes from other viral proteins with effects on cell cycle G2/M controls. PP2A appears to be a common viral target since other viruses such as simian virus 40 (SV40), polyoma virus, human T lymphotrophic retrovirus and adenovirus affect the enzymatic activity of at least a subset of PP2A proteins (see review [62]). Even though these viruses are not otherwise related, they all seem to have adapted a similar strategy to affect cellular processes by direct interaction with PP2A. Similar to the Vpr effects, both adenoviral E4orf4 [63-65] and HTLV Tax protein induce cell cycle G2 arrest [59]. These two viral proteins both bind to PP2A and affect its enzymatic activity $[63,66]$. Interestingly, similar to Vpr, Tax-induced G2 arrest is reversed by caffeine [59]. Further examinations indicated that Tax binds to CHK2 in Jurkat T-cells [59] but it complexes with CHK1 in other T-cells [67]. In contrast, the T-antigens of both SV40 and polyoma virus promote cell proliferation by down-regulation of PP2A through direct competition with the $\mathrm{B}$ regulatory subunit (Reviewed in [68]). Further studies on the interactions of Vpr and these other viral products with PP2A should provide additional insight into the role of PP2A in cell cycle $\mathrm{G} 2 / \mathrm{M}$ regulation.

\section{A NEW MODEL FOR CELL CYCLE G2/M TRAN- SITION}

Based on our current knowledge about the effect of Vpr on cell cycle G2/M regulation, a new model for the cell cycle G2/M transition is proposed for HIV-1 Vpr as shown in Fig. 1B. Although this new model may not be mutually exclusive from the classic G2/M checkpoint pathways (Fig. 1A), it nevertheless has the unique feature of a PP2A-mediated mechanism or mechanisms for G2/ $\mathrm{M}$ control by Vpr. We hypothesize that Vpr induces G2 arrest at least in part by going through an alternative cellular pathway(s) in which expression of $v p r$ activates PP2A activity either by direct association with the PP2A enzyme complex or by association with an intermediate protein(s)
$\mathrm{X}$. In addition, there may also be a concerted cellular mechanism which interlinks PP2A and ATR/CHK1 in the cellular response to $v p r$ during the induction of G2 arrest. A protein phosphorylation cascade (depicted as "?") including PP2A is probably in part responsible for activation of the mitotic inducer Wee1 by altering its phosphorylation levels, which in turn inhibits Cdc2 by Tyr 15 phosphorylation. While Wee1 plays the major role in the induction of G2 arrest by Vpr, Cdc25 appears to play a minor role and to be partially inhibited by this proposed regulatory pathway or by direct interaction with Vpr. Since overexpression of Sum1, a putative Cdc25 inhibitor, shows a synergistic effect with Vpr, Sum1 may be required by Vpr to inhibit Cdc25 either from upstream or downstream of Cdc25. Wos2 is another possible step in the pathway, and Vpr most likely inhibits Wos2 during the induction of G2 arrest. Since Wos2 physically interacts with Cdc2, Wos2 may be a downstream inhibitor of Weel (Fig. 1B). One possible mechanism for the inhibition of Weel activity by Wos 2 is that Wos 2 physical blocks the Tyr 15 phosphorylation site on Cdc2. Vpr might then inhibit Wos2 by preventing Wos 2 from binding to Cdc2. Based on the demonstrated similarities for cell cycle controls between fission yeast and human cells, it seems likely that pathway for Vpr-induced G2 arrest in fission yeast will also apply in most respects to that part of Vpr-induced G2 arrest in human cells which is not solely dependent on ATR.

\section{SUMMARY}

Besides the two most well-characterized cell cycle G2/ $M$ regulation pathways, i.e., DNA damage and replication checkpoints, some viral infections appear to modulate host cell cycle machinery in a fashion that is characteristically different from the classic checkpoints. This unique hostpathogen interaction is exemplified here in the induction of cell cycle G2 arrest by HIV-1 Vpr. PP2A seems to be a common cellular target for unrelated viruses. Therefore, further studies on the interactions of these viral proteins with PP2A and other related cellular factors should provide insight into the basic biology of cell cycle G2/M regulation and the biological significance of viral-induced G2 arrest during host-pathogen interactions.

\section{ACKNOWLDEGMENTS}

The work was supported in part by grants from the National Institute of Health GM89630 and AI63080, an endowed Research Scholar Chair by the Medical Research Institute Council, and by an internal grant of the University of Maryland Medical Center (RYZ).

\section{REFERENCES}

1 Boddy M, Furnari B, Mondesert O, Russell P. Replication check- 
point enforced by kinases Cds1 and Chk1. Science 1998; 280: 909-12.

2 Caspari T, Carr AM. DNA structure checkpoint pathways in Schizosaccharomyces pombe. Biochimie 1999; 81:173-81.

3 Elledge SJ. Cell cycle checkpoints: preventing an identity crisis. Science 1996; 274:1664-72.

4 Rhind N, Russell P. Mitotic DNA damage and replication checkpoints in yeast. Curr Opin Cell Biol 1998; 10:749-58.

5 Morgan DO. Principles of CDK regulation. Nature 1995; 374: 131-4.

6 Gould KL, Nurse P. Tyrosine phosphorylation of the fission yeast $c d c 2^{+}$protein kinase regulates entry into mitosis. Nature 1989; 342:39-45.

7 Krek W, Nigg EA. Differential phosphorylation of vertebrate p3 $4^{\text {cdc2 }}$ kinase at the G1/S and G2/M transitions of the cell cycle: identification of major phosphorylation sites. EMBO J 1991; 10:305-16.

8 Norbury C, Blow J, Nurse P. Regulatory phosphorylation of the $\mathrm{p} 34^{\text {cdc2 }}$ protein kinase in vertebrates. EMBO J 1991; 10:33219.

9 Nurse P. Checkpoint pathways come of age. Cell 1997; 91:865-7.

10 Rhind N, Russell P. Tyrosine phosphorylation of cdc2 is required for the replication checkpoint in Schizosaccharomyces pombe. Mol Cell Biol 1998b; 18:3782-7.

11 Walworth NC, Bernards R. rad-dependent response of the chk1encoded protein kinase at the DNA damage checkpoint. Science 1996; 271:353-6.

12 Burtelow MA, Roos-Mattjus PM, Rauen M, Babendure JR, Karnitz LM. Reconstitution and molecular analysis of the hRad9hHus1-hRad1 (9-1-1) DNA damage responsive checkpoint complex. J Biol Chem 2001; 276:25903-9.

13 Carr AM. DNA structure dependent checkpoints as regulators of DNA repair. DNA Repair (Amst) 2002; 1:983-94.

14 Caspari T, Carr AM. Checkpoints: how to flag up double-strand breaks. Curr Biol 2002; 12:R105-7.

15 Saka Y, Esashi F, Matsusaka T, Mochida S, Yanagida M. Damage and replication checkpoint control in fission yeast is ensured by interactions of Crb2, a protein with BRCT motif, with Cut5 and Chk1. Genes Dev 1997; 11:3387-400.

16 Francesconi S, Smeets M, Grenon M, et al. Fission yeast chk1 mutants show distinct responses to different types of DNA damaging treatments. Genes Cells 2002; 7:663-73.

17 Esashi F, Mochida S, Matsusaka T, et al. Establishment of and recovery from damage checkpoint requires sequential interactions of Crb2 with protein kinases Rad3, Chk1, and Cdc2. Cold Spring Harb Symp Quant Biol 2000; 65:443-9.

18 Furnari B, Rhind N, Russell P. Cdc25 mitotic inducer targeted by Chk1 DNA damage checkpoint kinase. Science 1997; 277: 1495-7.

19 Lopez-Girona A, Furnari B, Mondesert O, Russell P. Nuclear localization of Cdc25 is regulated by DNA damage and a 14-3-3 protein. Nature 1999; 397:172-5.

20 Baber-Furnari BA, Rhind N, Boddy MN, et al. Regulation of mitotic inhibitor Mik1 helps to enforce the DNA damage checkpoint. Mol Biol Cell 2000; 11:1-11.

21 al-Khodairy F, Carr AM. DNA repair mutants defining G2 checkpoint pathways in Schizosaccharomyces pombe. EMBO J 1992; 11:1343-50.

22 Alcasabas AA, Osborn AJ, Bachant J, et al. Mrc1 transduces signals of DNA replication stress to activate Rad53. Nat Cell
Biol 2001; 3:958-65.

23 Tanaka K, Russell P. Mrc1 channels the DNA replication arrest signal to checkpoint kinase Cds1. Nat Cell Biol 2001; 3:966-72.

24 Zeng Y, Forbes KC, Wu Z, et al. Replication checkpoint requires phosphorylation of the phosphatase Cdc25 by Cds1 or Chk1. Nature 1998; 395:507-10.

25 Rhind N, Russell P. Roles of the mitotic inhibitors Wee1 and Mik1 in the G(2) DNA damage and replication checkpoints. Mol Cell Biol 2001; 21:1499-508.

26 Shiloh Y. ATM and ATR: networking cellular responses to DNA damage. Curr Opin Genet Dev Feb 2001; 11:71-7.

27 Abraham RT. Cell cycle checkpoint signaling through the ATM and ATR kinases. Genes Dev 2001; 15:2177-96.

28 Sanchez Y, Wong C, Thoma RS, et al. Conservation of the Chk1 checkpoint pathway in mammals: linkage of DNA damage to Cdk regulation through Cdc25. Science 1997; 277:1497-501.

29 Cans C, Ducommun B, Baldin V. Proteasome-dependent degradation of human CDC25B phosphatase. Mol Biol Rep 1999; 26: 53-7.

30 Lammer C, Wagerer S, Saffrich R, et al. The cdc25B phosphatase is essential for the $\mathrm{G} 2 / \mathrm{M}$ phase transition in human cells. J Cell Sci 1998; 111:2445-53.

31 Mils V, Baldin V, Goubin F, et al. Specific interaction between 14-3-3 isoforms and the human $\mathrm{CDC} 25 \mathrm{~B}$ phosphatase. Oncogene 2000; 19:1257-65.

32 Bartek J, Lukas J. Pathways governing G1/S transition and their response to DNA damage. FEBS Lett 2001; 490:117-22.

33 Taylor WR, Stark GR. Regulation of the G2/M transition by p53. Oncogene 2001; 20:1803-15.

34 Graves PR, Lovly CM, Uy GL, Piwnica-Worms H. Localization of human Cdc25C is regulated both by nuclear export and 14-33 protein binding. Oncogene 2001; 20:1839-51.

35 Re F, Braaten D, Franke EK, Luban J. Human immunodeficiency virus type $1 \mathrm{Vpr}$ arrests the cell cycle in $\mathrm{G} 2$ by inhibiting the activation of p34cdc2-cyclin B. J Virol 1995; 69:6859-64.

$36 \mathrm{He}$ J, Choe S, Walker R, et al. Human immunodeficiency virus type 1 viral protein $\mathrm{R}$ (Vpr) arrests cells in the G2 phase of the cell cycle by inhibiting p34cdc2 activity. J Virol 1995; 69:670511.

37 Zhao Y, Cao J, O'Gorman MRG, Yu M, Yogev R. Effect of human immunodeficiency virus Type 1 protein $\mathrm{R}(v p r)$ gene expression on basic cellular functions of fission yeast Schizosaccharomyces pombe. J Virol 1996; 70:5821-6.

38 Elder RT, Yu M, Chen M, Edelson S, Zhao Y. Cell cycle G2 arrest induced by HIV-1 vpr in fission yeast (Schizosaccharomyces pombe) is independent of cell death and early genes in the DNA damage checkpoint. Virus Res 2000; 68:161-73.

39 Elder RT, Yu M, Chen M, et al. HIV-1 Vpr induces cell cycle G2 arrest in fission yeast (Schizosaccharomyces pombe) through a pathway involving regulatory and catalytic subunits of PP2A and acting on both Wee1 and Cdc25. Virology 2001; 287:359-70.

40 Bartz SR, Rogel ME, Emerman M. Human immunodeficiency virus type 1 cell cycle control: Vpr is cytostatic and mediates G2 accumulation by a mechanism which differs from DNA damage checkpoint control. J Virol 1996; 70:2324-31.

41 Yuan H, Kamata M, Xie YM, Chen IS. Increased levels of Wee1 kinase in $\mathrm{G}(2)$ are necessary for $\mathrm{Vpr}$ - and gamma irradiationinduced G(2) arrest. J Virol 2004; 78:8183-90.

42 Munoz MJ, Bejarano ER, Daga RR, Jimenez J. The identification of Wos2, a p23 homologue that interacts with Wee1 and 
Cdc2 in the mitotic control of fission yeasts. Genetics 1999; 153:1561-72.

43 Goh WC, Manel N, Emerman M. The human immunodeficiency virus Vpr protein binds Cdc25C: implications for $\mathrm{G} 2$ arrest. Virology 2004; 318:337-49.

44 Kino T, Pavlakis GN. Partner molecules of accessory protein $\mathrm{Vpr}$ of the human immunodeficiency virus type 1. DNA Cell Biol 2004; 23:193-205.

45 Kino T, Gragerov A, Valentin A, et al. Vpr protein of human immunodeficiency virus type 1 binds to $14-3-3$ proteins and facilitates complex formation with Cdc25C: implications for cell cycle arrest. J Virol 2005; 79:2780-7.

46 Masuda M, Nagai Y, Oshima N, et al. Genetic studies with the fission yeast Schizosaccharomyces pombe suggest involvement of wee1, ppa2, and rad24 in induction of cell cycle arrest by human immunodeficiency virus type 1 Vpr. J Virol 2000; 74: 2636-46.

47 Matsuoka S, Huang M, Elledge SJ. Linkage of ATM to cell cycle regulation by the Chk2 protein kinase. Science 1998; 282:18937.

48 Bentley NJ, Holtzman DA, Flaggs G, et al. The Schizosaccharomyces pombe rad3 checkpoint gene. EMBO J 1996; 15: 6641-51.

49 Savitsky K, Bar-Shira A, Gilad S, et al. A single ataxia telangiectasia gene with a product similar to PI-3 kinase. Science 1995; 268: 1749-53.

50 Zhu Y, Roshal M, Li F, Blackett J, Planelles V. Upregulation of survivin by HIV-1 Vpr. Apoptosis 2003; 8:71-9.

51 Zimmerman ES, Chen J, Andersen JL, et al. Human immunodeficiency virus type $1 \mathrm{Vpr}$-mediated G2 arrest requires Rad17 and Hus 1 and induces nuclear BRCA1 and gamma-H2AX focus formation. Mol Cell Biol 2004; 24:9286-94.

52 Mansky LM. The mutation rate of human immunodeficiency virus type 1 is influenced by the vpr gene. Virology 1996; 222: 391-400.

53 de Noronha CM, Sherman MP, Lin HW, et al. Dynamic disruptions in nuclear envelope architecture and integrity induced by HIV-1 Vpr. Science 2001; 294:1105-8.

54 Benko Z, Liang D, Agbottah E, et al. Anti-Vpr activity of a yeast chaperone protein. J Virol 2004; 78:11016-29.

55 Iordanskiy S, Zhao Y, DiMarzio P, et al. Heat-shock protein 70 exerts opposing effects on Vpr-dependent and Vpr-independent HIV-1 replication in macrophages. Blood 2004; 104:1867-72.

56 Iordanskiy S, Zhao Y, Dubrovsky L, et al. Heat shock protein 70 protects cells from cell cycle arrest and apoptosis induced by human immunodeficiency virus type 1 viral protein R. J Virol 2004; 78:9697-704.

57 Shimura M, Tanaka Y, Nakamura S, et al. Micronuclei formation and aneuploidy induced by Vpr, an accessory gene of human immunodeficiency virus type 1. FASEB J 1999; 13:621-37.

58 Zhao Y, Yu M, Chen M, et al. Pleiotropic effects of HIV-1 protein $\mathrm{R}(\mathrm{Vpr})$ on morphogenesis and cell survival in fission yeast and antagonism by pentoxifylline. Virology 1998; 246: 266-76.

59 Haoudi A, Daniels RC, Wong E, Kupfer G, Semmes OJ. Human T-cell leukemia virus-I tax oncoprotein functionally targets a subnuclear complex involved in cellular DNA damage-response. J Biol Chem 2003; 278:37736-44.

60 Roshal M, Kim B, Zhu Y, Nghiem P, Planelles V. Activation of the ATR-mediated DNA damage response by the HIV-1 viral protein R. J Biol Chem 2003; 278:25879-86.

61 Poon B, Grovit-Ferbas K, Stewart SA, Chen ISY. Cell cycle arrest by $\mathrm{Vpr}$ in HIV-1 virions and insensitivity to antiretroviral agents. Science 1998; 281:266-9.

62 Janssens V, Goris J. Protein phosphatase 2A: a highly regulated family of serine/threonine phosphatases implicated in cell growth and signalling. Biochem J 2001; 353:417-39.

63 Kornitzer D, Sharf R, Kleinberger T. Adenovirus E4orf4 protein induces PP2A-dependent growth arrest in Saccharomyces cerevisiae and interacts with the anaphase-promoting complex/ cyclosome. J Cell Biol 2001; 154:331-44.

64 Roopchand DE, Lee JM, Shahinian S, et al. Toxicity of human adenovirus E4orf4 protein in Saccharomyces cerevisiae results from interactions with the Cdc55 regulatory B subunit of PP2A. Oncogene 2001; 20:5279-90.

65 Shtrichman R, Sharf R, Barr H, Dobner T, Kleinberger T. Induction of apoptosis by adenovirus E4orf4 protein is specific to transformed cells and requires an interaction with protein phosphatase 2A. Proc Natl Acad Sci U S A 1999; 96:10080-5.

66 Fu DX, Kuo YL, Liu BY, Jeang KT, Giam CZ. Human Tlymphotropic virus type I tax activates I-kappa B kinase by inhibiting I-kappa B kinase-associated serine/threonine protein phosphatase 2A. J Biol Chem 2003; 278:1487-93.

67 Park HU, Jeong JH, Chung JH, Brady JN. Human T-cell leukemia virus type 1 Tax interacts with Chk1 and attenuates DNAdamage induced G2 arrest mediated by Chk1. Oncogene 2004; 23:4966-74.

68 Rundell K, Parakati R. The role of the SV40 ST antigen in cell growth promotion and transformation. Semin Cancer Biol 2001; 11:5-13. 